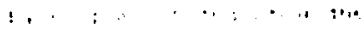

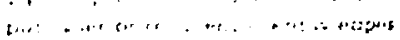

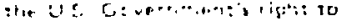

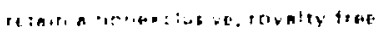

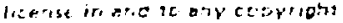

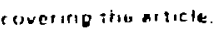

OPSERVATIONS OF ARCING IN THE ISX TOAAMAK"

P. MIODUSZEWSKI

(Reported by J. T. Hogan)

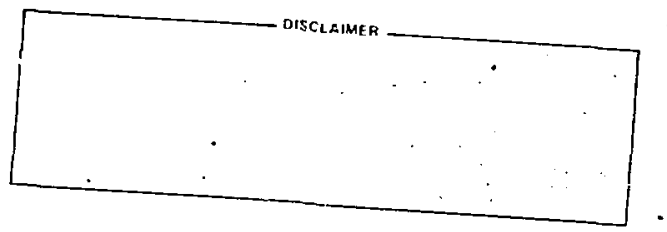

Fusion Energy Division

Oak Ridge National Laboratory

Oak Ridge, Tennessee 37830

* Research sponsored by the Office of Fuston Energy (ETM), U.S. Department of Energy under contract l:-7405-cng-26 with the linion Carbide Corporation. 
Observations of Arcing in the ISX Tokamak*

P. Mioduszewsk:

(reported by J.T. Hogan) 


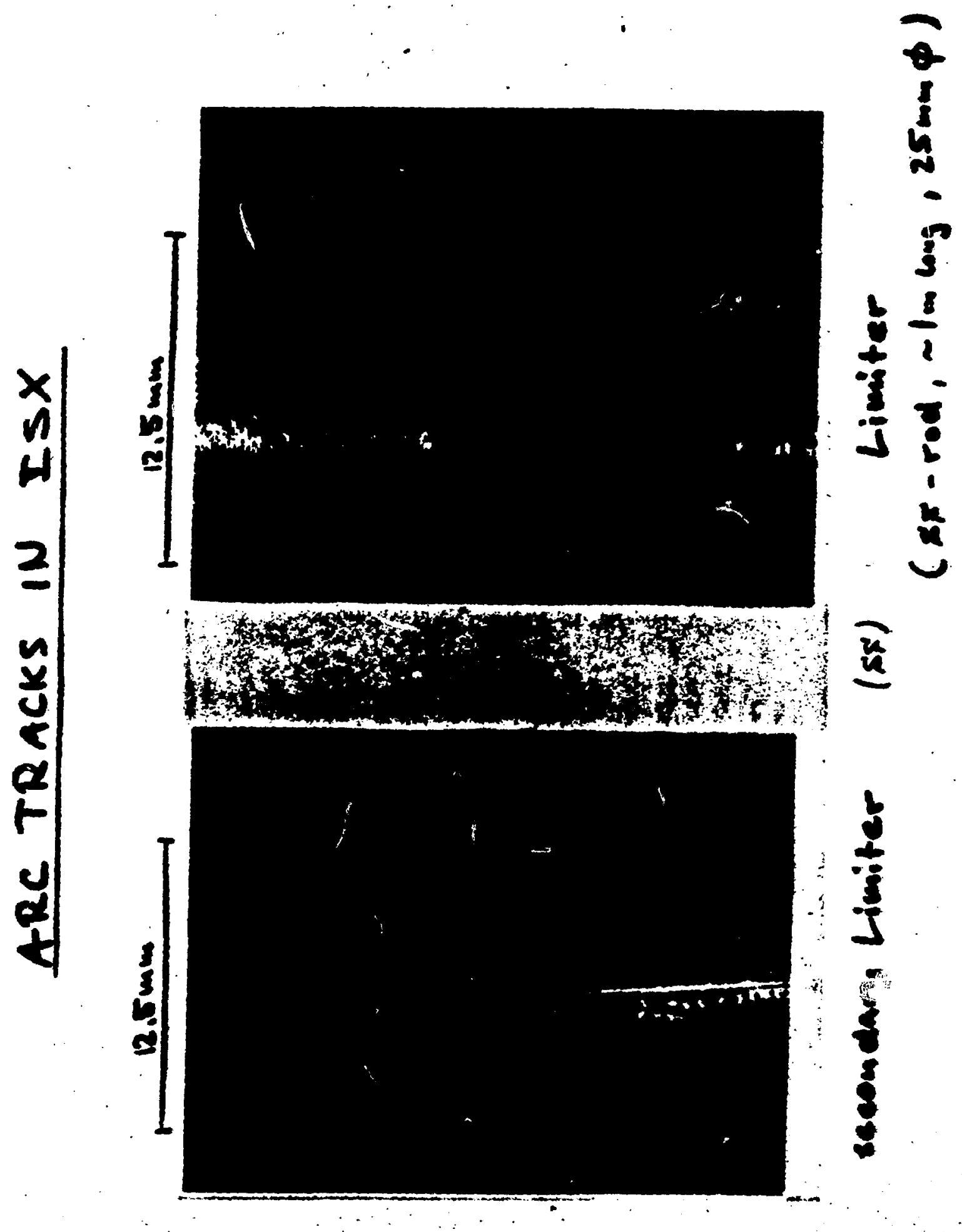


- Arc tracks have been observed in ISX on the stainless steel and graphite limiters, on stainless steel and AL-probes and on parts of - the first wall

- The amount of removed material corresponds to about $10^{16}-10^{18}$ atoms per arc track

- To find ont whether or not arcing occurs during critical phases of the discharge a real time experiment with electrical and optical are defection has been net up in Is $X$ 


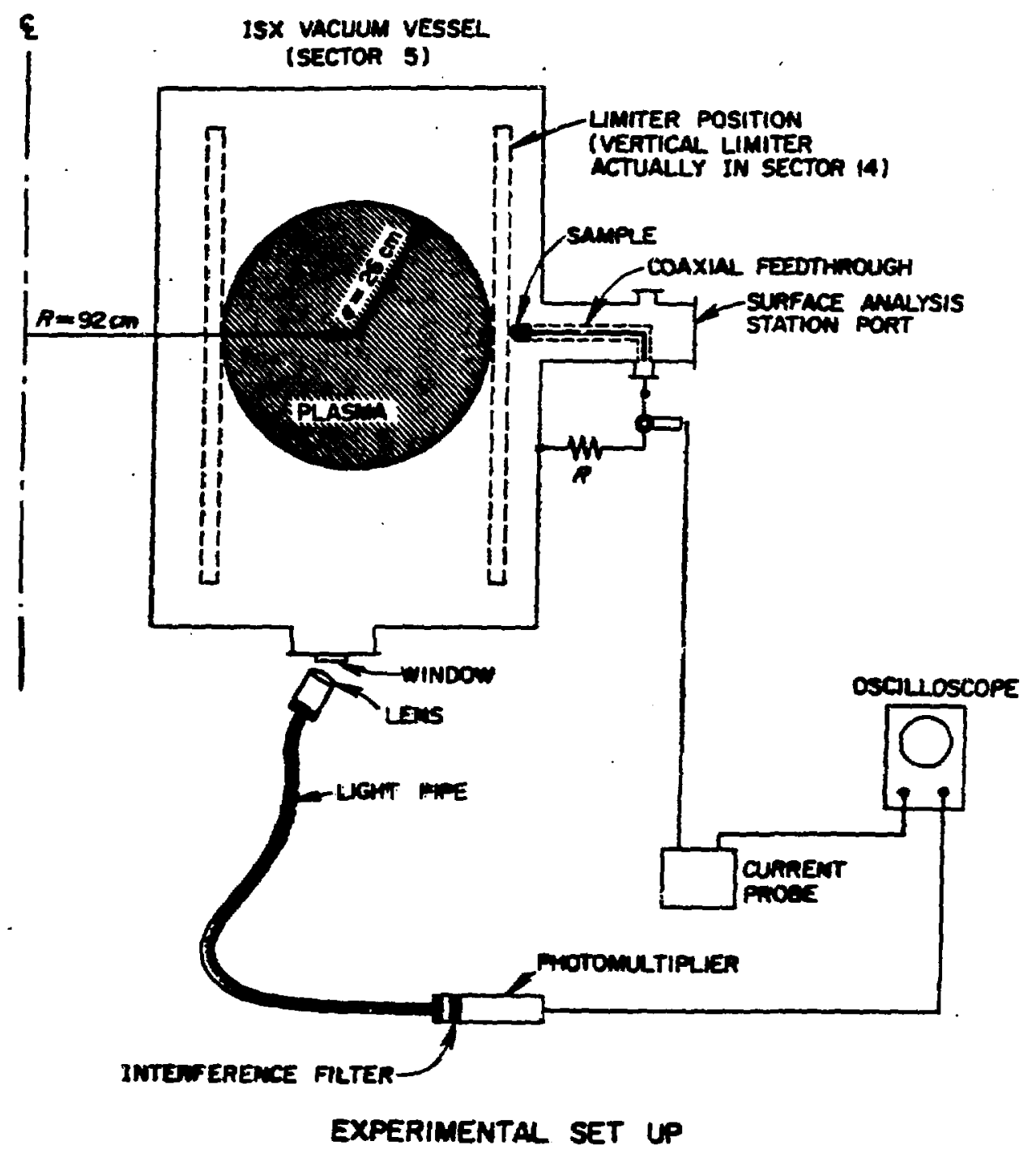


1. Conditioning Phase

- When the tokamak has been rented (up to air) and/or now components are installed (probes, limiters) strong arcing is being observed.

- After a conditioning phase ( $x 100$ shots) the arcing probability decreases considerably.

- After the conditioning phase arcing is no longer being observed throughout the discharge but only during certain phases. 


15 of

$: 10$

W. - a

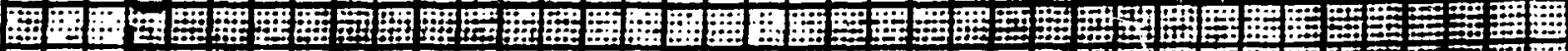

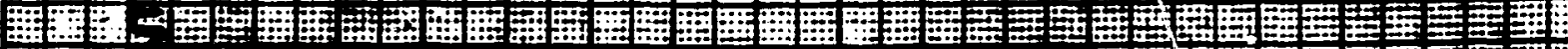

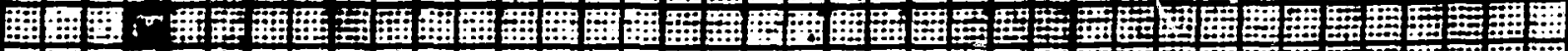

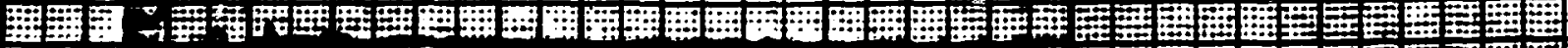

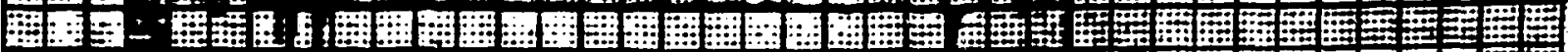
H.5

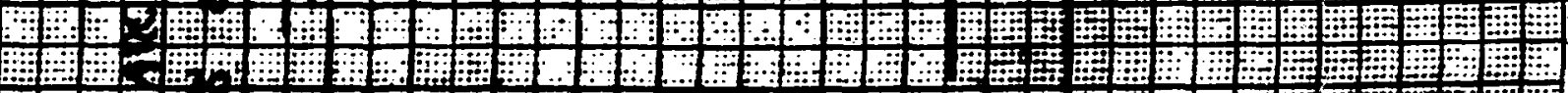
T)

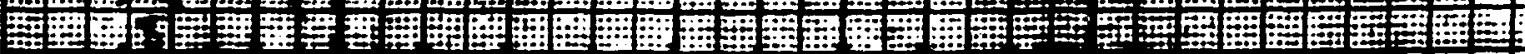

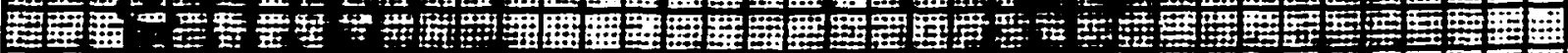

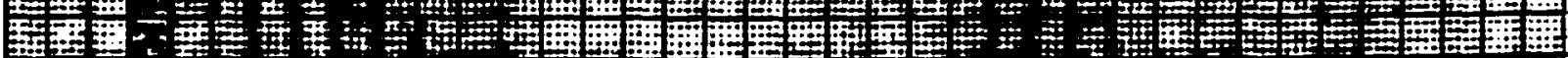

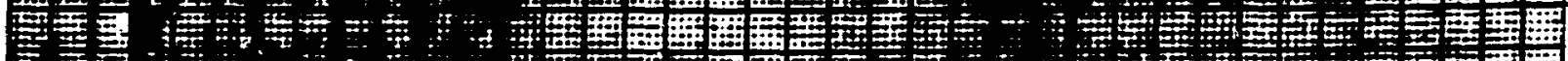

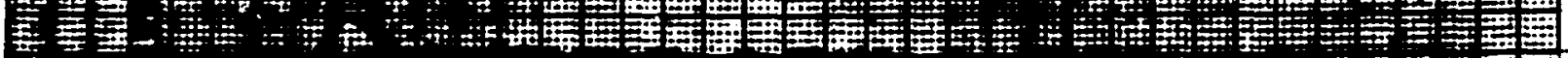

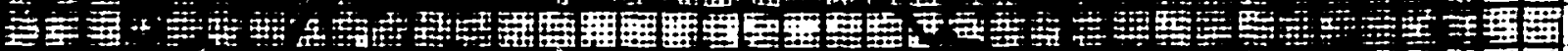

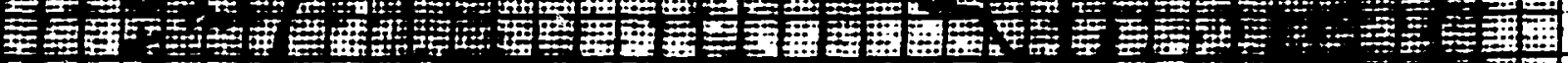

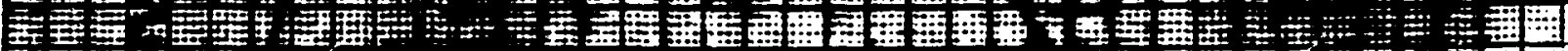

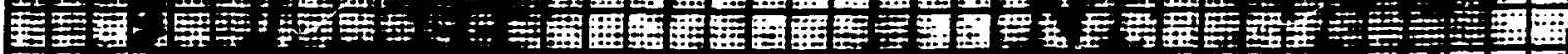

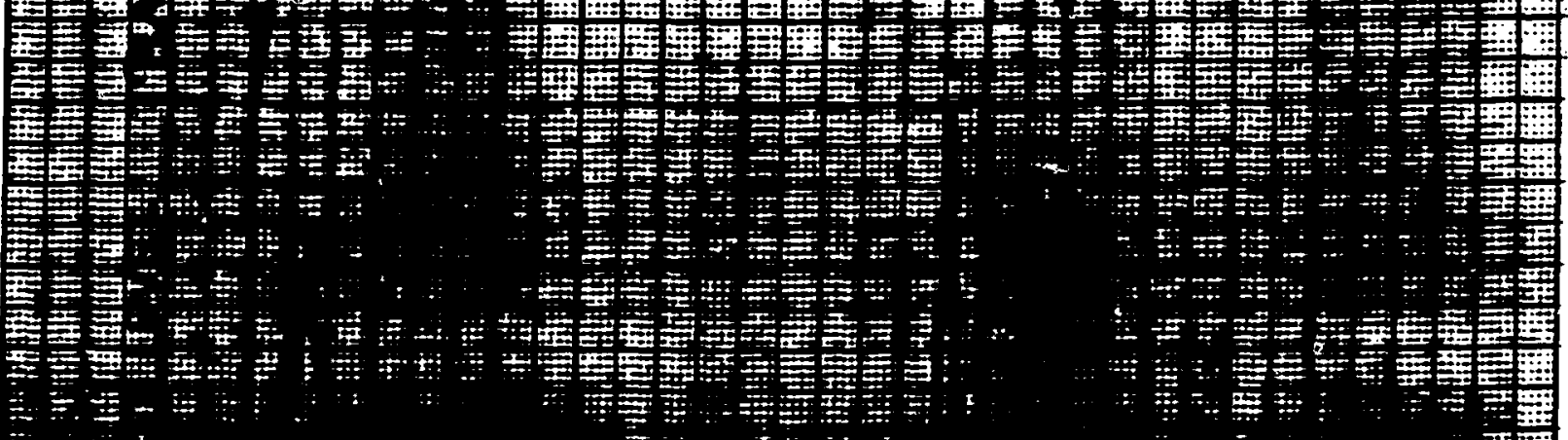

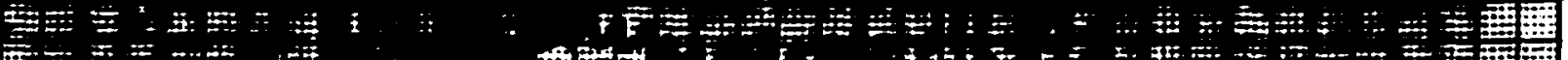

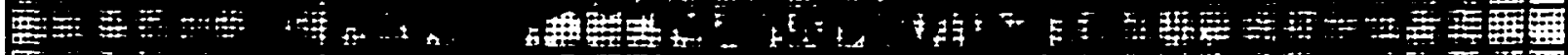
焉地

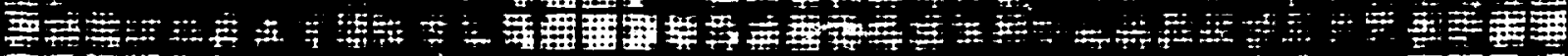

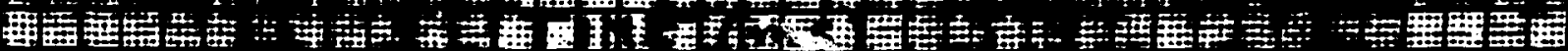

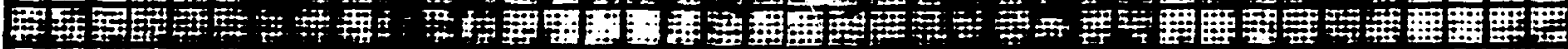

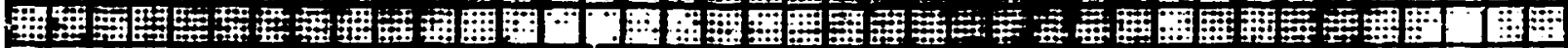

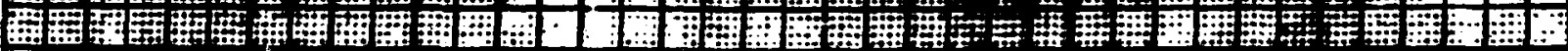

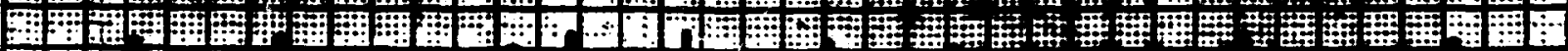

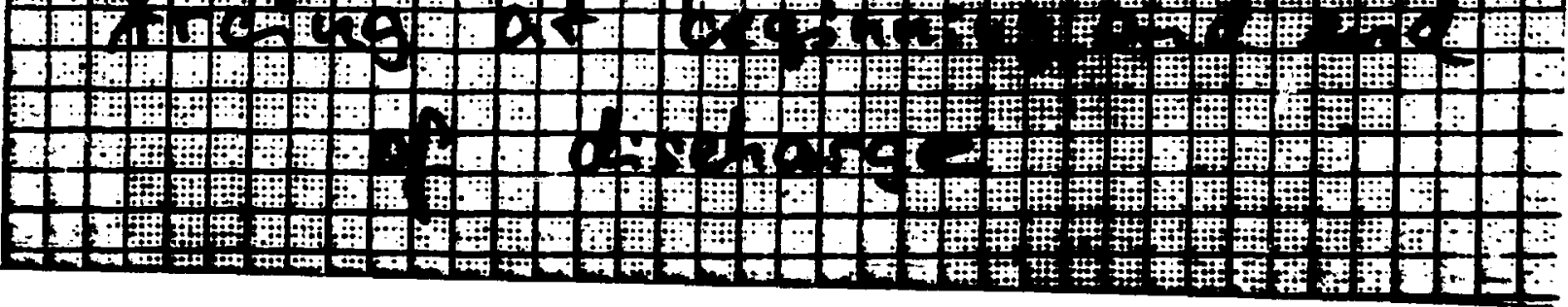




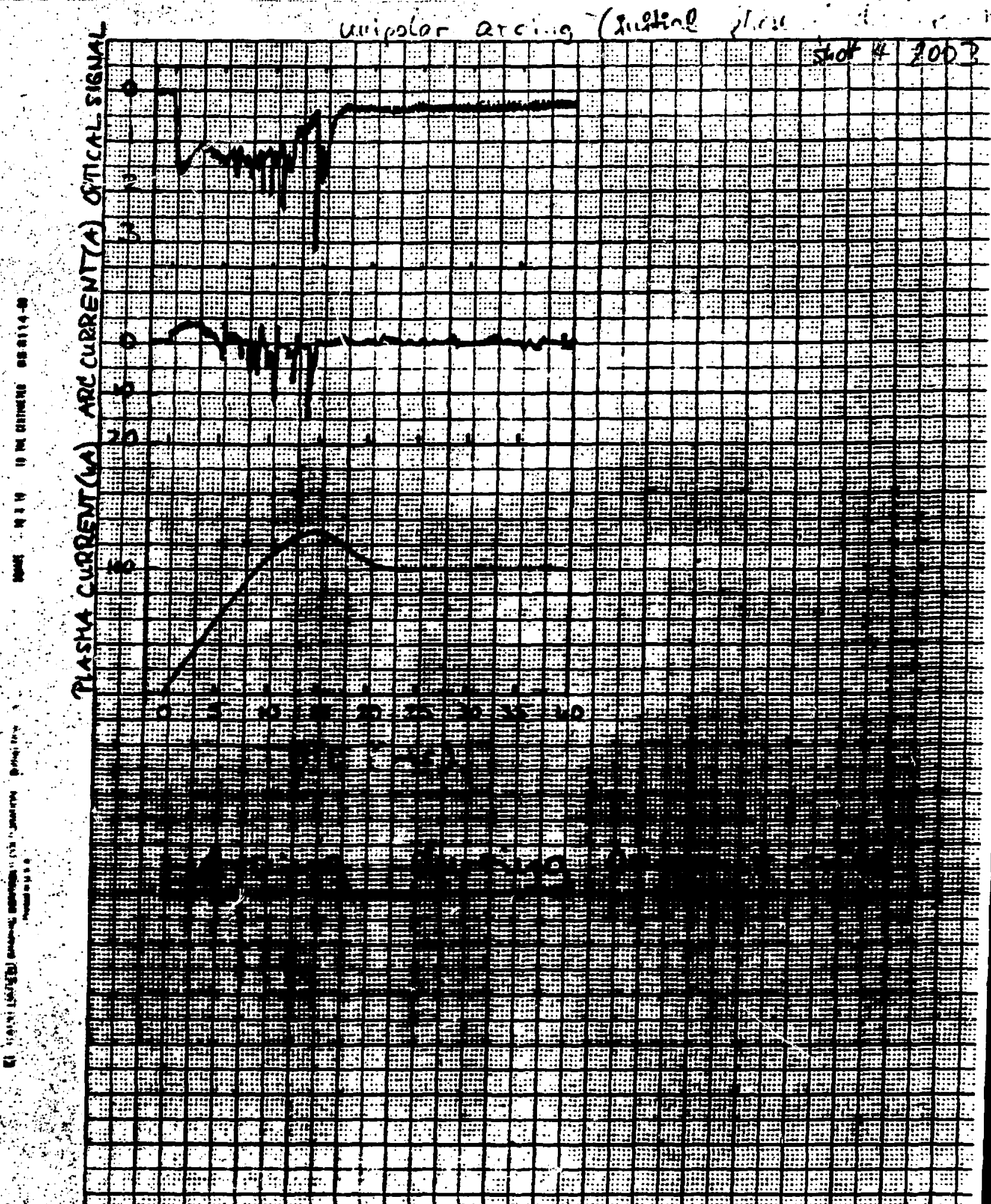


Arcing during minor disruptions 
2. Equilibrium State

Arcing is being observed during phases of poor plasma confinement:

a) current rise phase

b) minor and major disruptions

c) discharge end

During these phases the plasma density and /or temperature at the Cimiter/wall exceeds presumably the conditioning parameters.

This behaviour is being maintained even after thousands of discharges. 


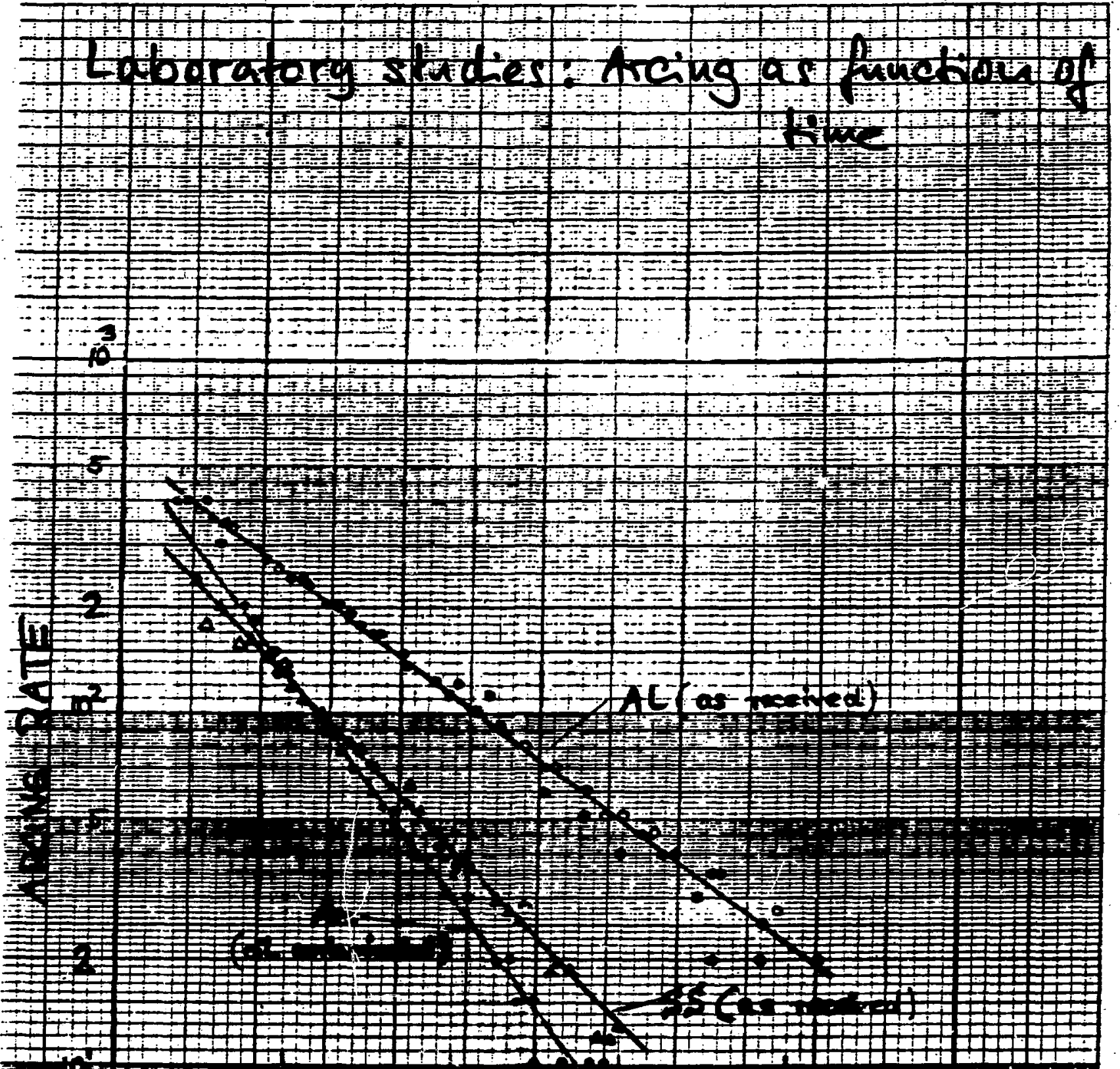

(1)




\section{Conditioning effect}

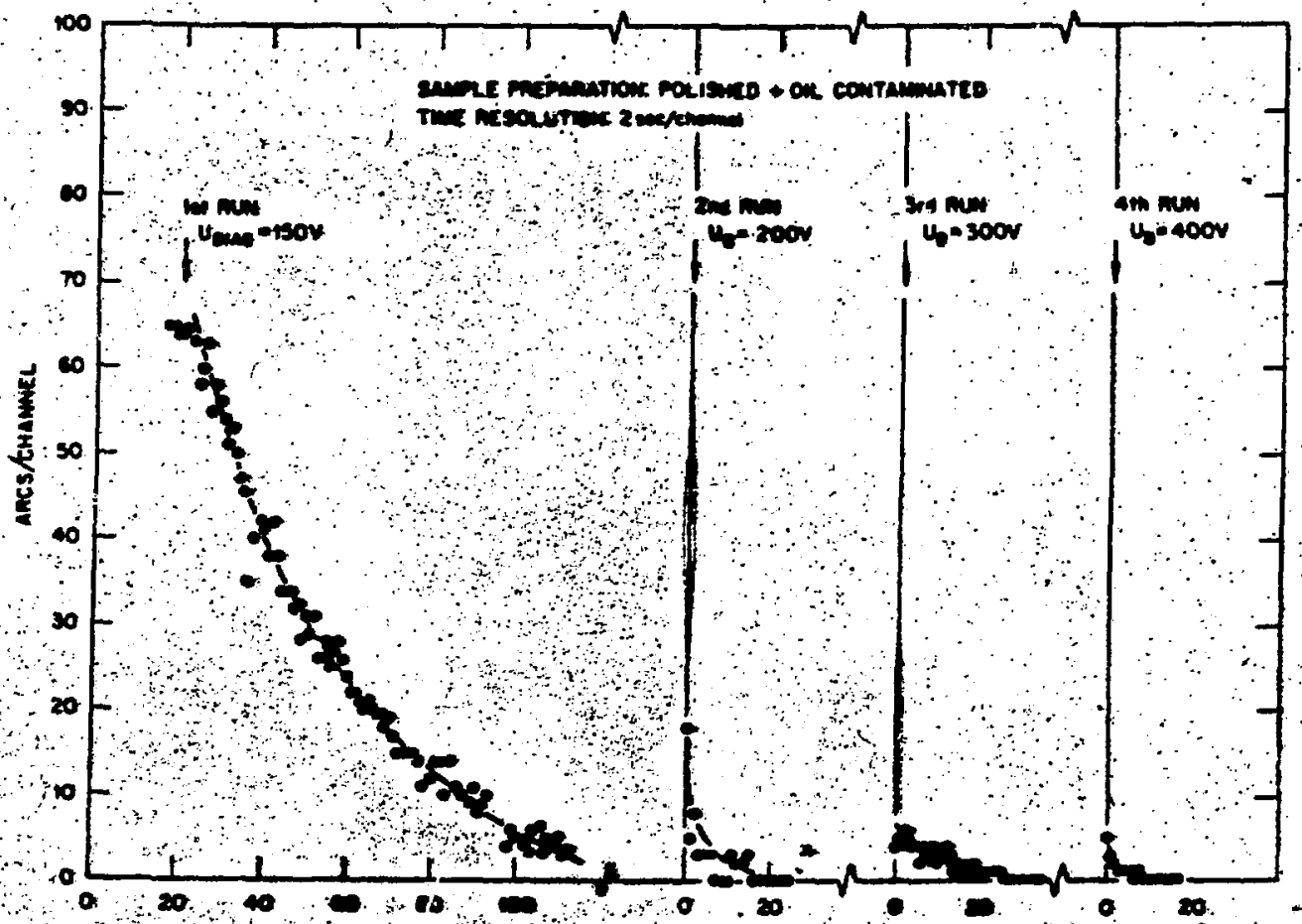

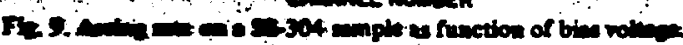

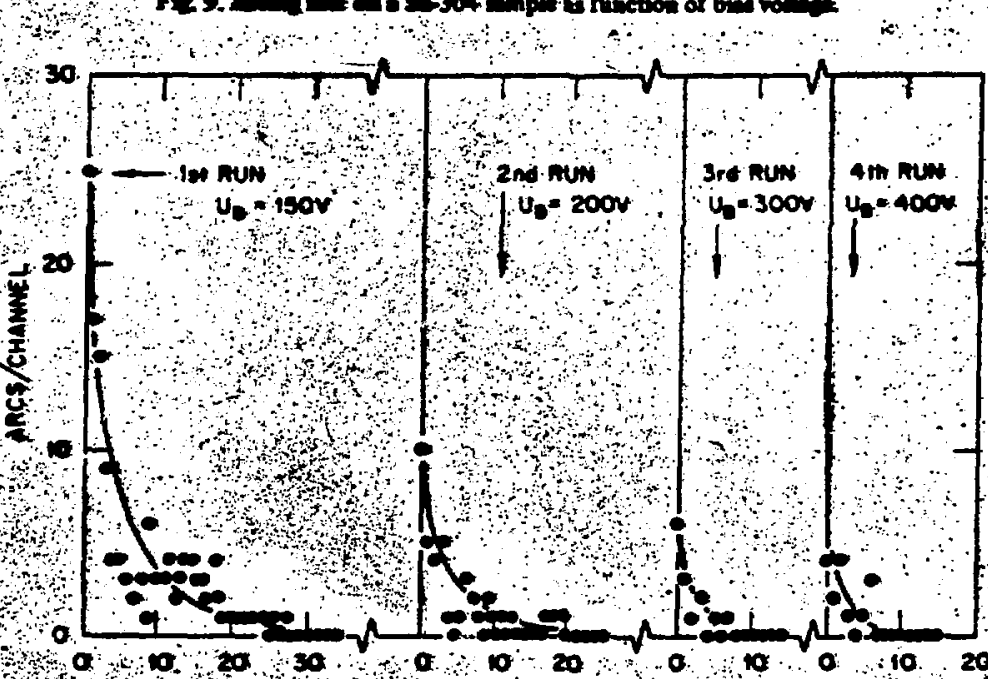

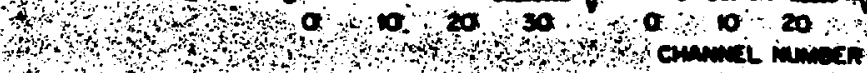

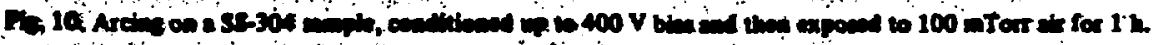
and 


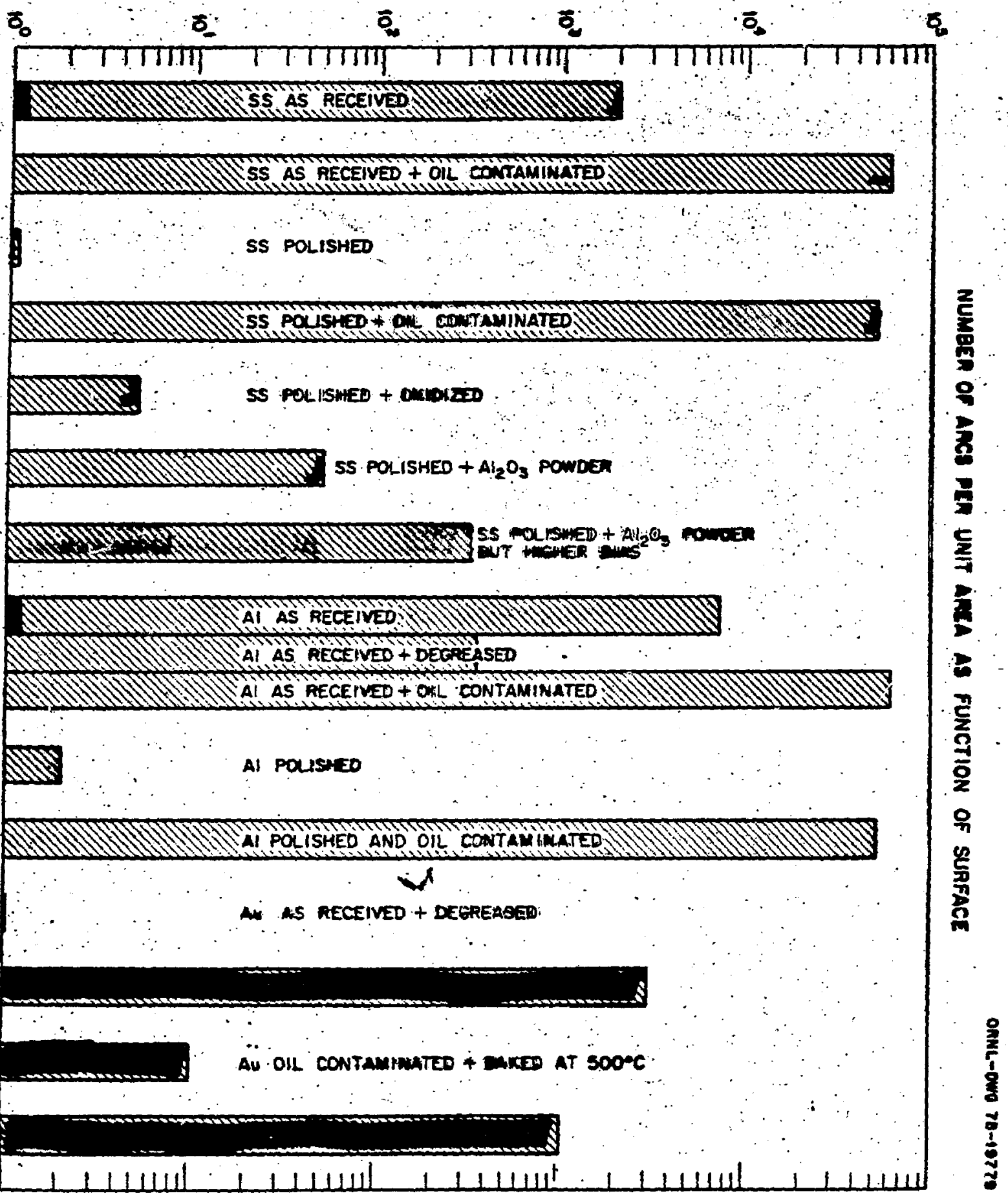


Supporting laboratory experiments to study the conditioning phase

Observations:

a) At given plasma- and surface conditions the arcing probability decreases exponentially.

b) A change of bias voltage (plasma con = ditions) and tor surface conditions produces additional arcing.

c) The arcing behaviour is predómi = rattly a function of the surface conditions 
Confusions - conditioning phase

- The conditioning process seems to be very effective for type cathode spot arcs (burning in surface contaminants)

- Raising plasma density/temperature above the conditioning parameters requires further conditioning at the new parameters.

- When the plasma conditions get severe enough to initiate type 2 ares the conditioning might no longer be effective. (higher densities and temperatures in future machines) 
Conclusions - equilibrium state

- Impurities introduced during the current rise phase do not affect the main part of the discharge due to the short impurity con: finement time $(\approx 20 \mathrm{~ms})$.

- Arcing during disruptions does not seem to be a problem because the discharge is out of control anyway.

- Arcing at the discharge end can obisionsly not affect the main portion of the discharge.

Medium - and ligh-z impurity introduction can, however, turn a minor into $a$ major disruption or con turn a spf discharge tericination Into a major distortion. $\rightarrow$ (INTSOR) of disruptions of a $100 \mathrm{hJ}$ plasma 

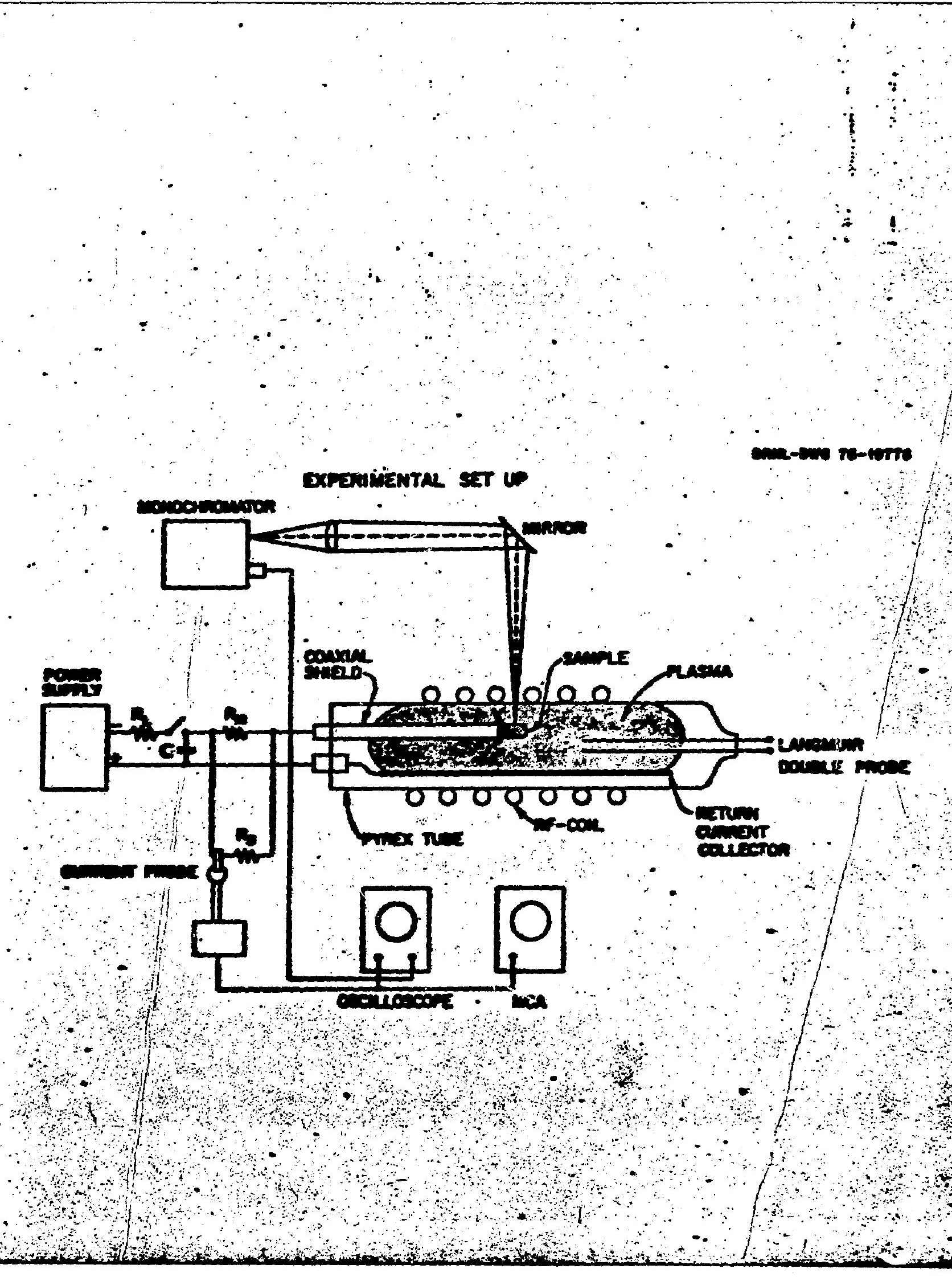